\title{
Numerical and Experimental Study on Optimization of Coil Springs used in Vehicles' Suspension System
}

\author{
Mostafizur Rahman*, Saeem Bin Abdullah \\ Department of Mechanical Engineering, Chittagong University of Engineering and Technology, \\ Chattogram-4349, Bangladesh.
}

Received: July 28, 2021, Revised: September 24, 2021, Accepted: September 30, 2021, Available Online: October 03, 2021

\begin{abstract}
In general, the suspension systems are used to absorb vibrations, bump, rolls, dip from shock loads due to road surface irregularities. It performs its major role without affecting the vehicles' stability and overall handling during operation. Coil springs are used as suspension element in light vehicles to attenuate unwanted vibrations. A spring is an elastic object used to store mechanical energy and it can be twisted, pulled or extended by some force and can return to its initial position when the force is released. In this study, mild steel material was taken into consideration in designing and fabricating coil springs. Theoretical and experimental investigations were conducted to calculate springs' stiffness and to make validation between them. Three model of springs having coils $10,11,14$ respectively are designed which have slight stiffness difference both theoretically and experimentally. The models were analyzed to determine mechanical behaviors for randomly chosen loading conditions ranging from $29.4 \mathrm{~N}$ to $176.4 \mathrm{~N}$ which are better suited with spring size. It is noted from both numerical and experimental investigations that deflection is high when the stiffness is less and viceversa. In addition, shear stress formation increases with the increment of stiffness and applied load. Hence, springs having high stiffness are used in suspension system to reduce vibration and other disturbances. This study shows springs of having high stiffness are comparatively compact in size and cost economic as well.
\end{abstract}

Keywords: Suspension system, Coil spring, Stiffness, Deflection, Stress formation.

This work is licensed under a Creative Commons Attribution-Non Commercial 4.0 International License.

\section{Introduction}

Automobile engineering known as automotive engineering deals with design, development, manufacturing, and safety testing field of vehicles. Automotive engineering, aerospace engineering, and naval architecture are branch of vehicle engineering that incorporates mechanical, electrical, and control engineering elements applied to the design, manufacturing, and operation of vehicles. Automotive manufacturing needs a big team of experts specializing in particular elements. These specializations include aerodynamics, mechanics of machineries, control systems, and control of emissions [1]. In addition, it involves improved modification on suspension system as well. Suspension systems are used to carry load, maintain a good contact between road and wheel, to improve handling as well as ride quality, which are sometimes at conflict [2]. Suspension mechanism connects a vehicle to its wheels and allows relative motion between them. It includes tires, springs, shock absorbers, and linkages. Furthermore, three main elements, which are used in suspension system of vehicles, are the wishbones, springs, and mostly the shock absorber [3]. These elements are used not to transmit the exerted forces from the road surface in the vehicle body. The first workable spring suspension required extensive metallurgical knowledge and ability, and it was only conceivable with the onset of industrialization that it became possible [4]. The above mentioned suspension elements are very sophisticated parts in engineering applications. Hence, proper investigations are needed to conduct by both numerically and experimentally to get concrete results before using them in engineering applications. Springs namely coil, compression, tension, torsional, leaf, and many more springs are used in suspension system. Coil springs are widely used in light vehicles' suspension system due to its outstanding mechanical properties and easy manufacturing. A variety of mechanical behaviors, reliability, and life cycles are needed to study considering real operating conditions before using them in automobile because replacing, maintenance would take time and matter of cost as well if failure is occurred often and then. That's why Das et al. [5] investigated failure analysis of helix shaped man-made coil springs used in passenger car. Authors modified coil diameter, spring mean diameter, free length, and amount of coil turns per unit length to make the optimal design. They showed that springs normally fail owing to elevated cycle fatigue where the stress applied is below the point of yield strength and the charging cycle is more than $10^{5}$ cycles /sec. In addition, premature failure of coil spring's suspension was investigated and it was failed after some months putting into services. However, Vukelic et al. [6] studied failure analysis of coil springs used in motor vehicle suspension system for different static and cyclic loading condition. Furthermore, Nohut et al. [7] analyzed failure probability of ceramic coil springs. Ceramic springs are accessible commercially and a thorough assessment of reliability of these parts, would be helpful for their implementation in advanced engineering applications. In Contrast, Pastorcic et al. [8] conducted failure and fatigue analysis of coil springs used in light vehicles. The failed coil springs were examined to determine the causes of fracture using experimental procedures such as, visual observations, optical, and scanning electron microscopy. Furthermore, Assaad Alsahlani et al. [9] investigated design and failure of coil springs in vehicles using finite elements method. Suspension system in vehicle plays a very significant role to absorb and dissipate energy so that the suspension systems can offer the passengers comfortness, safety riding, and mechanical stability as well. Authors performed 
spring simulation using Solid Works 2018 with particular measurements and analyzed it with ANSYS 14 finite element analyzer. Researches are needed to carry out on spring materials to find out best one which shows outstanding mechanical properties operating by various conditions. Logavigneshwaran et al. [10] investigated design, fabrication, and analysis of helical coil springs made of alloy steel used in suspension systems so that it could withstand the deformation occurred in springs. Authors also demonstrated the application of composite materials to fabricate helical coil springs. In addition, Tausif M. Mulla et al. [11] researched the stress analysis of helical coil compression springs made of ASTM A227 used in Indian automotive market's three-wheeler auto-rickshaw. Quasi-static approach to the assessment of finite elements in the time domain was used to predict the fatigue life of the helical compression coil springs. Model of Morrow and model of Smith-Watson Topper were used under variable amplitude charging for fatigue life calculations for the springs. It is noted that, Sreenivasan et al. [12] investigated use of different fibre materials to fabricate springs used in suspension systems and assessed their performance. Autodesk inventor was used to design a suspension system and ansys 16.0 software was used to perform Finite element analysis (FEA). Comparative structural analysis was carried out using different loads in relation to the motorcycle's payload to calculate the overall deformation, stress, and strain of the suspension in static conditions. In contrast, Sathish et al. [13] investigated the optimal methods to design and production of coil spring using lathe centre. The tumbler gear mechanism is used to form a coil spring on lathe machine which is powered by a simple electric motor having variable operating speeds. To the authors of best knowledge, springs made of various materials used in suspension systems are needed to design and fabricate robustly to improve reliability, performances, and life cycles considering real operating conditions. Deep numerical and experimental studies are needed to conduct to access their properties. This study focuses on optimization on coil springs used suspension systems by both numerically and experimentally.

\section{Methodology and Design}

\subsection{Methodology}

Fig. 1 shows the total procedures followed in this study as analyzing the dimensions of springs, designing three springs using solidWORKS, fabricating three springs using required material in workshop, evaluation of properties and optimization of the designs by different tests, and analyzing results and recommendation for use.

\subsection{Design}

Three model of springs having stiffness of $2000 \mathrm{~N} / \mathrm{m}, 2500$ $\mathrm{N} / \mathrm{m}$, and $3000 \mathrm{~N} / \mathrm{m}$ are designed using solidWORKS and theirs parameters are chosen accordingly. Fig. 2 shows a model of coil spring used in suspension system [14], where $\mathrm{D}=$ spring coil mean diameter $(\mathrm{mm}), \mathrm{Do}=$ spring coil's outside diameter $(\mathrm{mm})$, $\mathrm{Di}=$ spring coil's inside diameter $(\mathrm{mm}), \mathrm{d}=$ spring wire's diameter, $\mathrm{N}=$ active coils number, $\mathrm{N} \_\mathrm{t}=$ number of total coil, $\mathrm{G}=$ modulus of rigidity of the spring materials, $\mathrm{F}=$ spring's axial load, $\mathrm{C}=$ spring index, $\mathrm{P}=$ pitch $(\mathrm{mm}), \mathrm{L}=$ spring's free length $(\mathrm{mm}), \mathrm{K}=\mathrm{Wahl}$ factor, $\mathrm{k}=$ spring stiffness.

Fig. 3 represents the designed three model of springs varying their parameters. Fig. 3 (a) shows a typical coil spring model and spring model 1 , spring model 2 , spring model 3 , and fabricated spring are shown in Fig. 3 (b), Fig. 3 (c), Fig. 3 (d), and Fig. 3 (e) respectively.

shows the specifications of the designed and fabricated springs. It is worthy to mention that three models are designed and fabricated just varying number of coils and other parameters keeping unchanged. It is noted that spring model 2 is more stiffened than spring model 1 and spring model 3 is more stiffened than both.

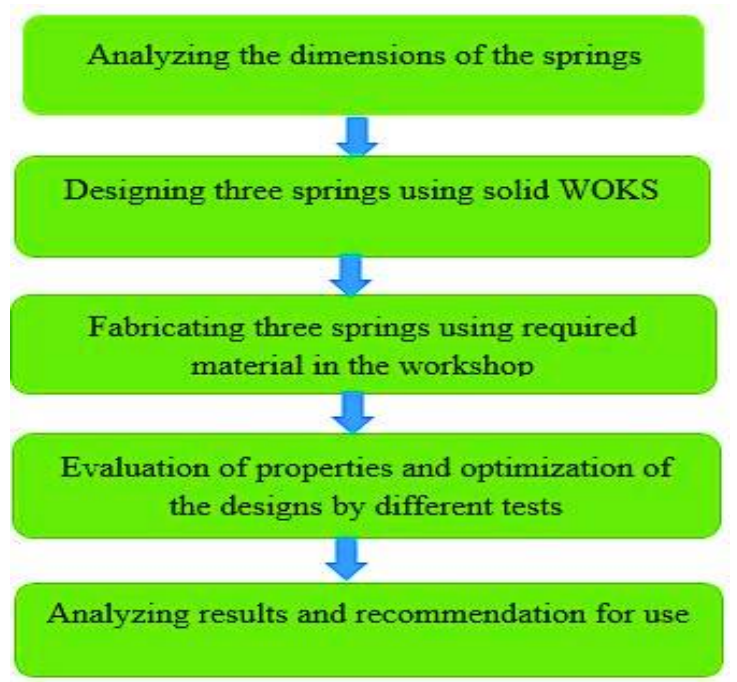

Fig. 1 Flow diagram of research work

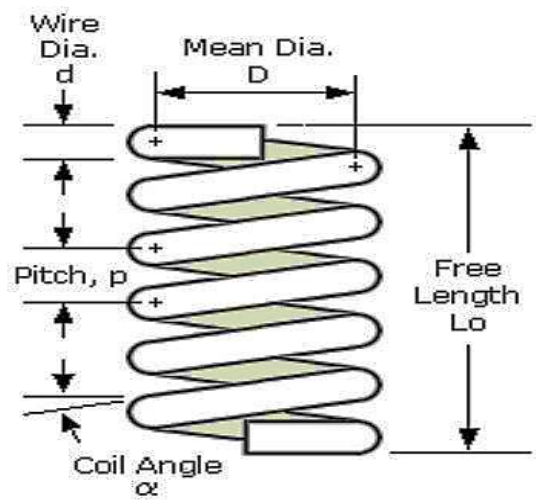

Fig. 2 Terminology used in spring design (Design adapted from [14])

Equation (1) is used to calculate spring stiffness theoretically, where $\mathrm{G}$ is the modulus of rigidity of spring material. Spring deflections and actual stiffness of springs are determined using Eq. (2), where $\partial$ is the deflection of spring end from its equilibrium position. Equation (3) is used to calculate shear stress developed in the springs for various loading.

Spring stiffness,

$\mathrm{k}=\frac{G \times d^{4}}{8 \times D^{3} \times N} \mathrm{~N} / \mathrm{mm}$

Spring deflection,

$\eta=\frac{J}{2 \pi} \cdot \frac{K_{T}}{K_{Q}}$

Shear stress,

$\eta=\frac{J}{2 \pi} \cdot \frac{K_{T}}{K_{Q}}$ 
Table 1 Specifications of the springs

\begin{tabular}{|c|c|c|c|c|c|c|}
\hline SI. No. & Name & $\begin{array}{c}\text { Wire dia. (d), } \\
\mathrm{mm}\end{array}$ & $\begin{array}{c}\text { Mean coil dia. (D), } \\
\mathrm{mm}\end{array}$ & No. of coil (N) & Free length, mm & Stiffness (k), N/m \\
\hline 01 & Model 1 & 4 & 45 & 14 & 165.10 & 2000 \\
\hline 02 & Model 2 & 4 & 45 & 11 & 165.10 & 2500 \\
\hline 03 & Model 3 & 4 & 45 & 10 & 165.10 & 3000 \\
\hline
\end{tabular}

(a)

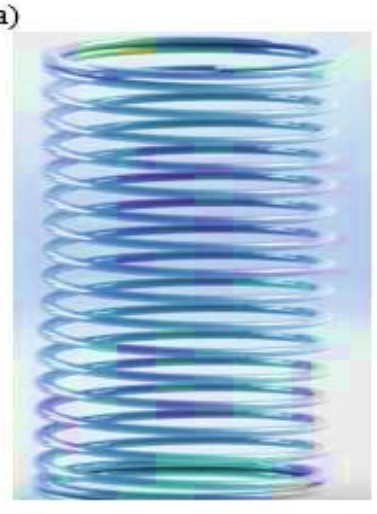

(b)

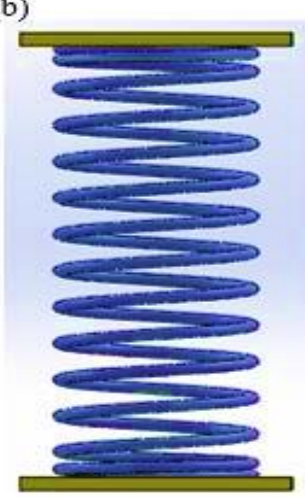

(c)

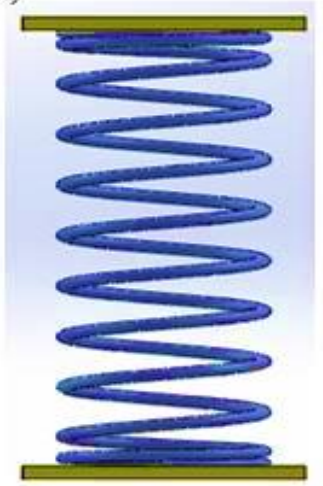

(d)

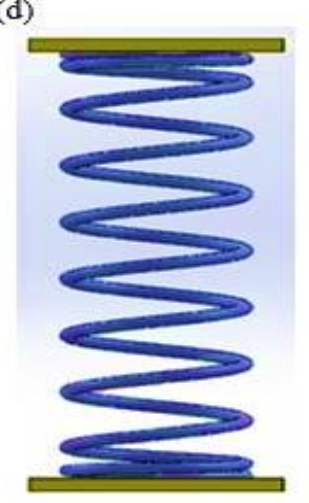

(e)

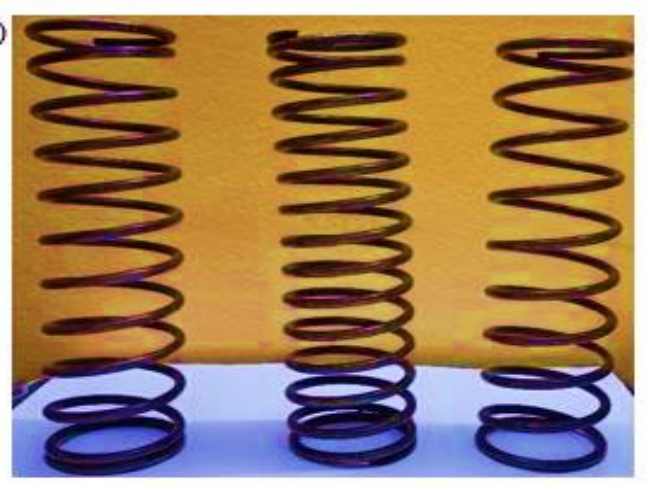

Fig. 3 Graphical representation of (a) a typical spring design (b) spring model 1 (c) spring model 2 (d) spring model 3 (e) fabricated springs

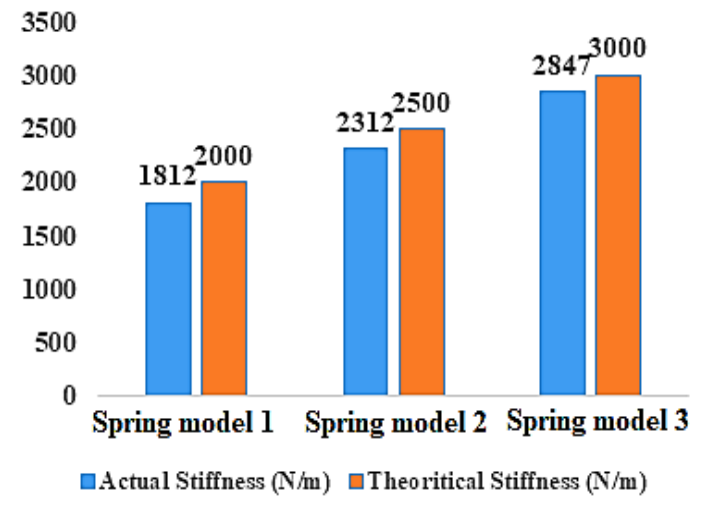

Fig. 4 Variation between actual and theoretical stiffness of designed springs

However, small amount of alloying elements in mild steel makes it comparatively inexpensive when compared to other steels [15]. The price, weldability, and machinability of this mild steel make it a popular customer choice. Spring assembly machine is used to manufacture those springs. In addition, spring stiffness and spring deflections are measured using Camry spring tester machine. A variety of deflections are taken for different applied load. Load values and deflections are taken from display. Theoretical and actual stiffness of the models are calculated and a little bit variation is observed as shown in Fig. 4 due to fabrication errors. Deformation variation and stress formation variation are observed due to this stiffness difference which is discussed later.

\section{Results and Discussion}

Three model of designed springs are simulated using various conditions to understand their mechanical behaviors that are helpful to predict fatigue failure, reliability, and life cycles. Static structure analysis was performed taking boundary conditions of springs fixed both end on a flat plate. Exact chemical and mechanical properties of mild steel are taken into account for simulating. Low stiffness spring element constraint method is used to give different loads on spring ends. Applied loading values ranging from $29.4 \mathrm{~N}$ to $176.4 \mathrm{~N}$ are chosen randomly and used in the both simulation and experimental process. Loading values and other conditions could be varied in real operating cases. However, those results would be useful to reach in concrete decision in designing coil springs used in suspension system. Fig. 5 shows deflection variation of springs for $29.4 \mathrm{~N}$. It is noticed that $16.022 \mathrm{~mm}$ deflection has been observed for spring model 1 whereas, $12.511 \mathrm{~mm}$ deflection for spring model 2, and $11.158 \mathrm{~mm}$ deflection for spring model 3. Equation (2) termed as 'deflection measurement of springs' signifies that spring deflection decreases with decrease of turns [16]. Springs are designed considering operating conditions so that good performances can be obtained. 
(a)

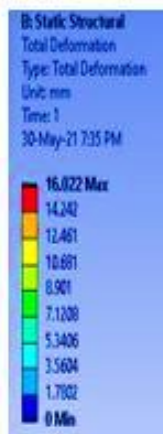

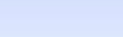

(b)

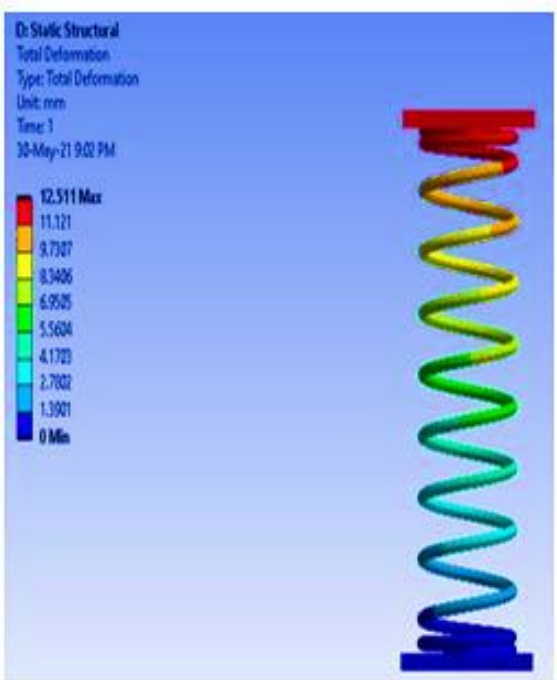

(c)

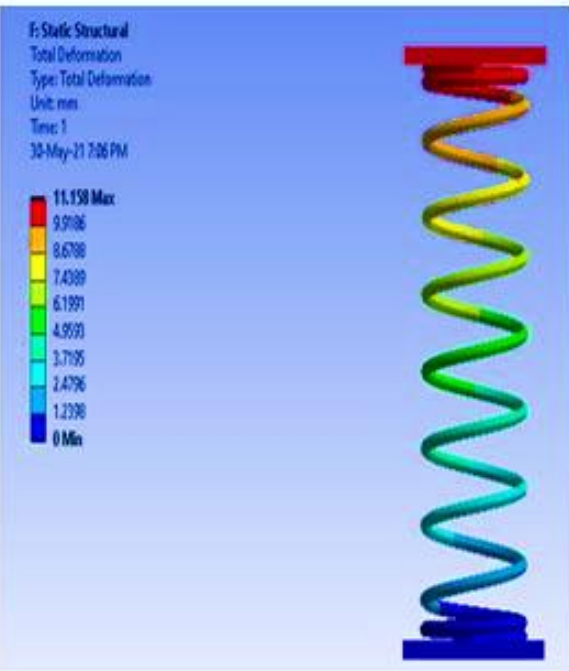

Fig. 5 Variation of deflection for $29.4 \mathrm{~N}$ load on (a) spring model 1 (b) spring model 2 (c) spring model 3

(a)

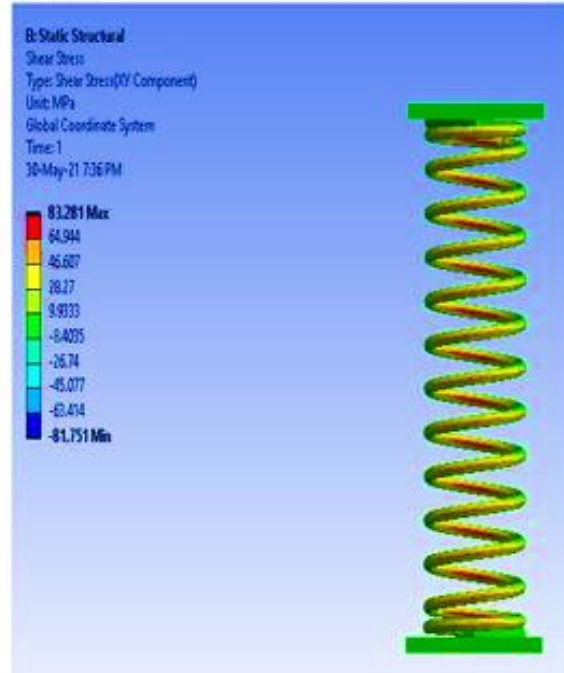

(b)

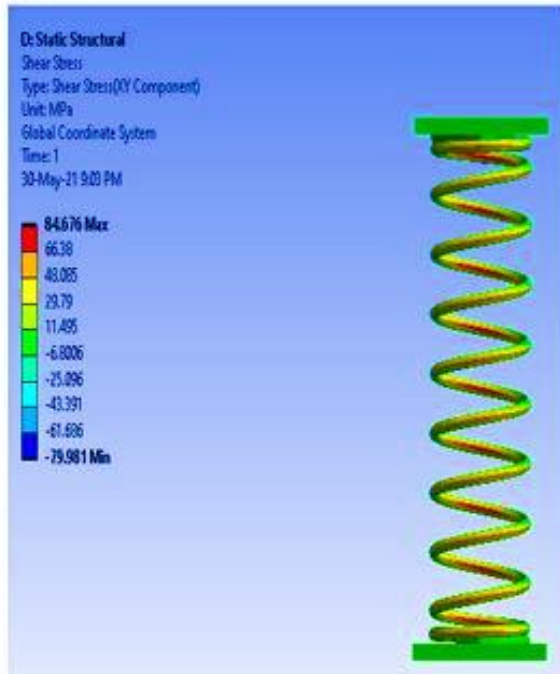

(c)

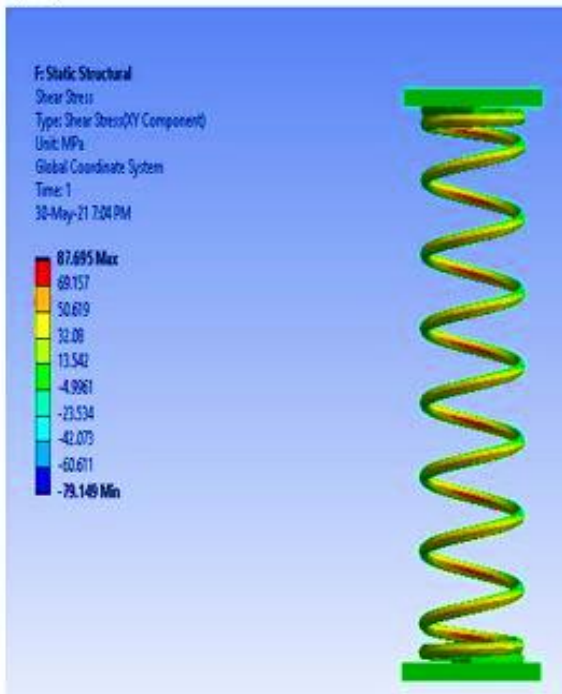

Fig. 6 Variation of shear stress for $29.4 \mathrm{~N}$ load on (a) spring model 1 (b) spring model 2 (c) spring model 3

(a)

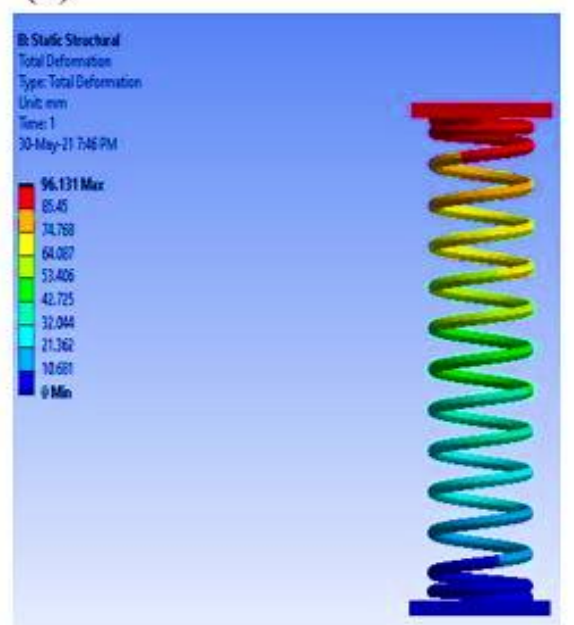

(b)

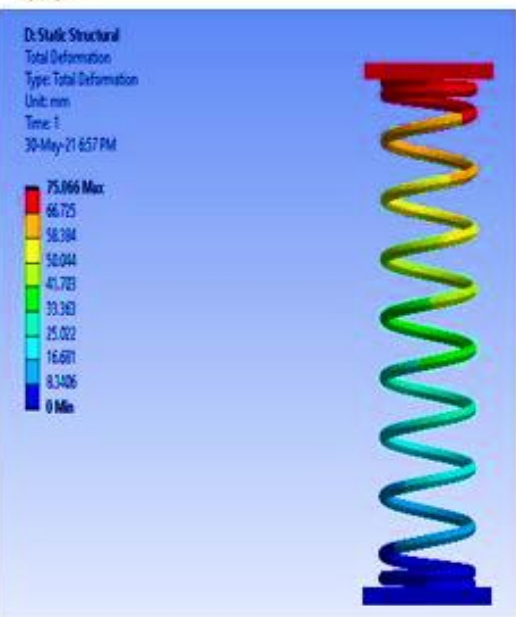

(c)

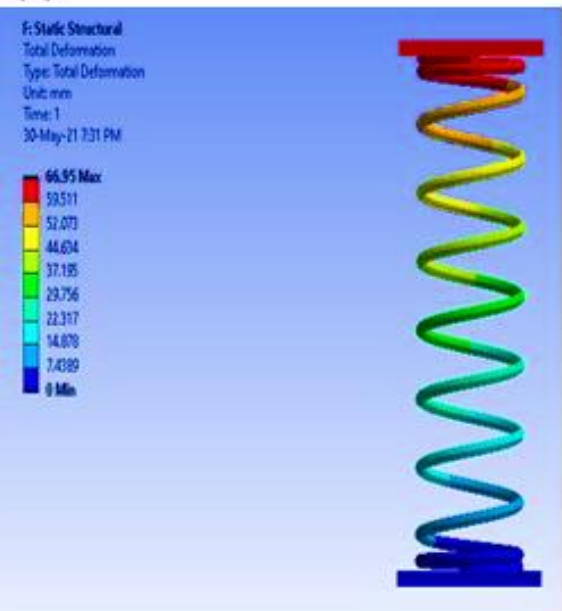

Fig. 7 Variation of deflection for $176.4 \mathrm{~N}$ load on (a) spring model 1 (b) spring model 2 (c) spring model 3 
(a)

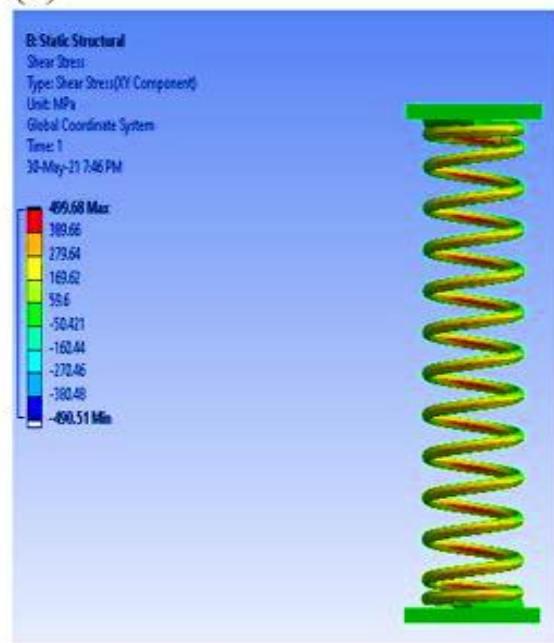

(b)

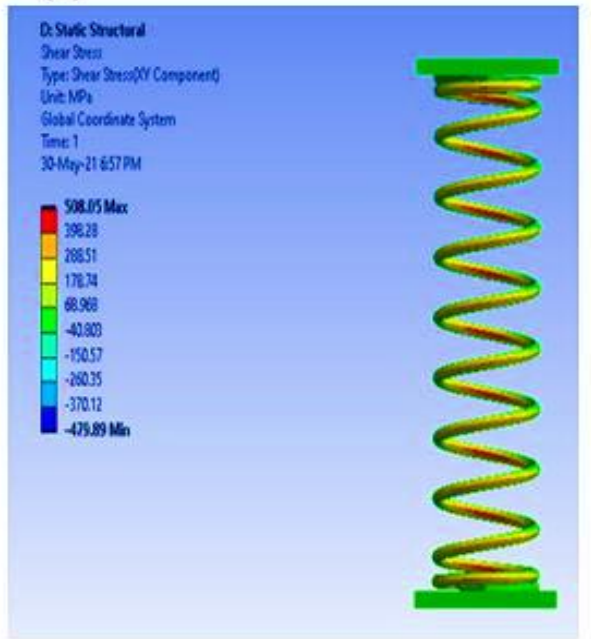

(c)

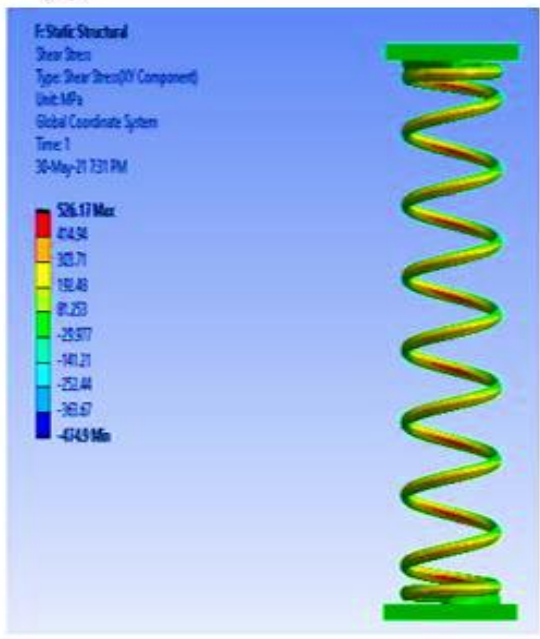

Fig. 8 Variation of shear stress for $176.4 \mathrm{~N}$ load on (a) spring model 1 (b) spring model 2 (c) spring model 3

It is known to all that stress is formed on mechanical parts subjected to static, dynamic, and cyclic loading conditions [17]. Parts are designed as they can withstand those stressed conditions to provide satisfactory performances. Stress variation on three designed springs having different turns are shown in Fig. 6. Maximum 87.695 MPa stress has been found to form on spring model 3, whereas, 83.281 MPa stress on spring model 1 and 84.676 MPa on spring model 2.

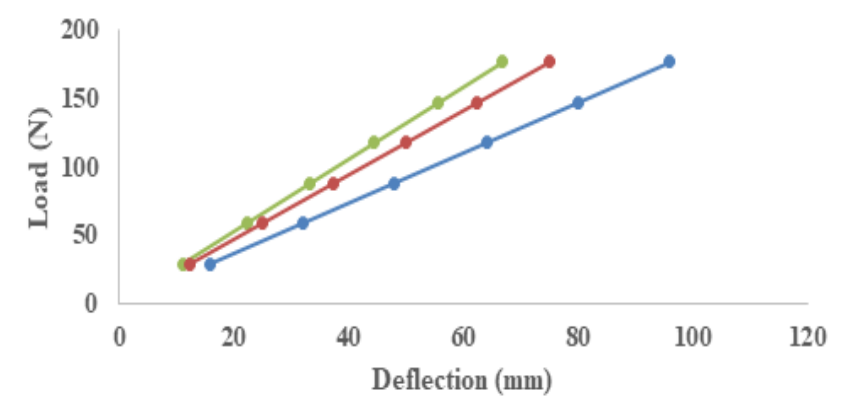

$\rightarrow$ Spring model $3 \quad \rightarrow$ Spring model 2

Fig. 9 Variation of theoretical deflection for loads on designed springs

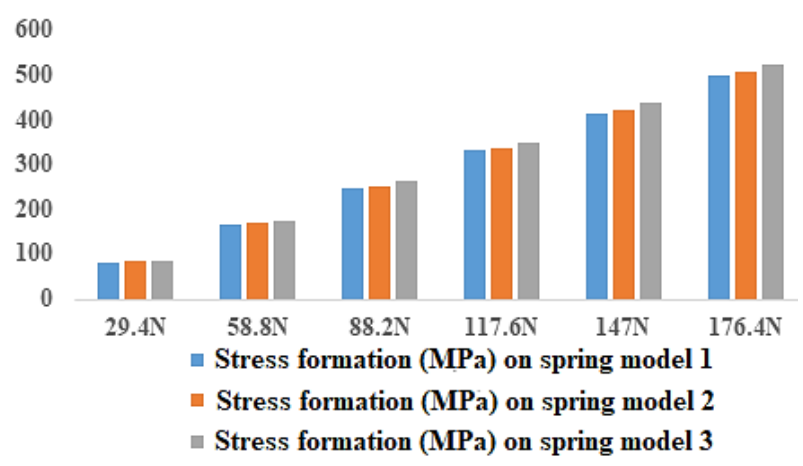

Fig. 10 Variation of theoretical shear stress for loads on designed springs

Furthermore, it is noticed that $96.131 \mathrm{~mm}$ deflection has been observed for spring model 1, $75.066 \mathrm{~mm}$ for spring model 2, and $66.95 \mathrm{~mm}$ for spring model 3 due to $176.4 \mathrm{~N}$ load as shown in Fig. 7. In addition, maximum 526.17 $\mathrm{MPa}$ stress has been found to form on spring model 3, 508.08 Mpa for model spring 2 , and $499.68 \mathrm{MPa}$ for spring model 1 . Moreover, those springs were also simulated for loading values $58.8 \mathrm{~N}, 88.2 \mathrm{~N}, 117.6 \mathrm{~N}$, and $147 \mathrm{~N}$ to make a comparison of their behaviors as shown in Fig. 10, Fig. 11 and Fig. 12.

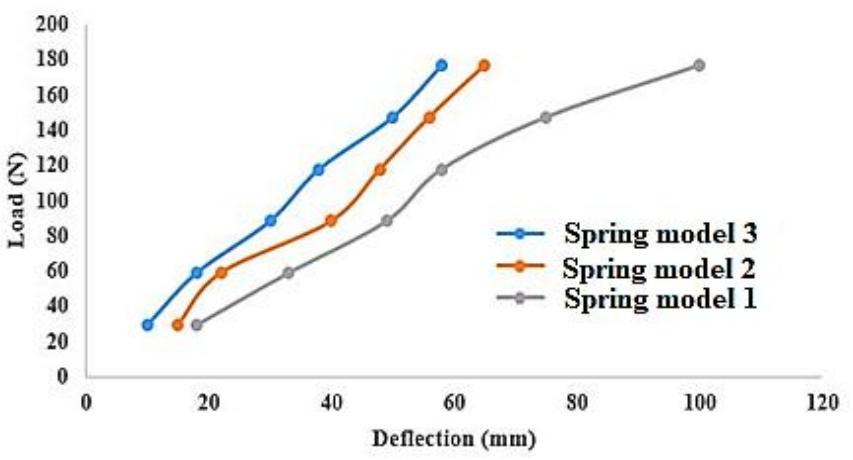

Fig. 11 Variation of experimental deflection for loads on designed springs

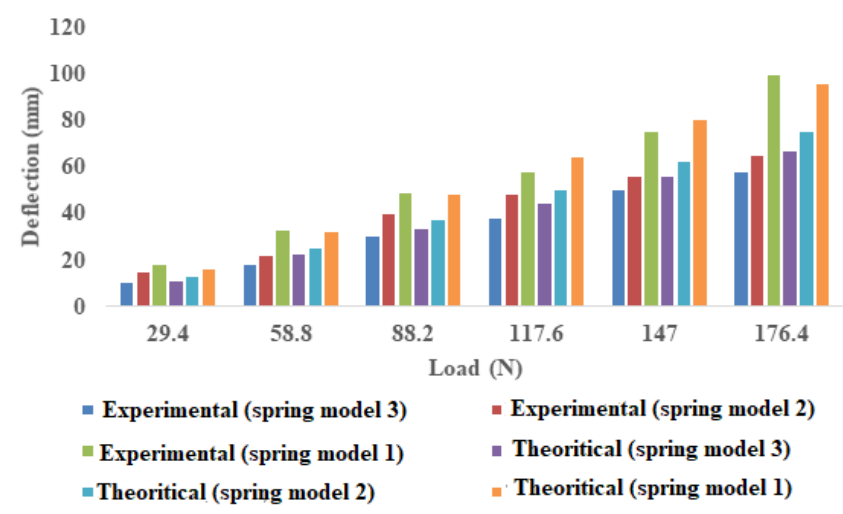

Fig. 12 Variation of actual and experimental deflection for loads on designed springs

According to spring force Eq. (2), deflection is increased with the increase of spring force [16]. Fig. 9 represents the proportional increase of deflection with the change of Load. The horizontal axis represents deflection in $\mathrm{mm}$ and the vertical axis represents the load in Newton. It is noted spring model 1 shows maximum deflection and spring model 3 shows minimum deflection for a specific load. Hence, it is concluded that springs are designed as per requirements to fulfill static loading conditions. Equations (1) - (2) which represent that spring deflection decreases with the decrease of turns. Decreasing 
spring turns keeping other parameters unchanged increases spring stiffness. Spring deflection decreases with increase of stiffness for a specific load as from Eq. (2). Lowering number of spring turns and keeping all parameters unchanged are making springs optimized in sense of size, weight, and cost also. This is main theme of this study to optimize coil springs used in vehicles' suspension system. In addition, Fig. 10 represents the variation of shear stress developed on each design for every specific load. It is noticed that the shear stress is increasing with the increase of applied load. Shear stress formation increases with the increase of stiffness and spring model 3 validates this. Shear stress is maximum on spring model 3 for every specific load whereas, shear stress developed on spring model 2 is less than spring model 3 but more than spring model 1 for every specific load.

It is known to all that experimental results do not validate $100 \%$ accurately the aforementioned theories due to some human, technical, and methodological errors. Fig. 11 represents experimental deflection of springs with the increase of load. Loads have been applied on the three designed springs using a spring tester having a digital display. It is clearly noticeable that the deflection is increasing but it is not proportional like the theoretical deflection as shown before. For every specific load, spring model 3 shows comparatively less deflection than spring model 2 and spring model 1. A slight deflection difference is observed between spring model 2 and spring model 1 . On the contrary, noticeable deflection difference is observed in case of spring model 1.

Fig. 12 shows a detailed comparative representation between theoretical and experimental deflection of designed springs for six loads. A little bit difference has been observed between theoretical and experimental results for every specific load on each design due to slight stiffness difference.

\section{Conclusion}

This study represents design, fabrication, analysis, and size optimization of coil springs used in vehicles' suspension system. Springs are designed varying number of turns and keeping other parameters unchanged. Mild steel was used to fabricate those springs due to its low cost and easy availability. Stiffness was calculated theoretically and experimentally before performing simulation and experimental investigations. A slight stiffness difference was observed due to impurities in materials, human, technical, and methodological errors throughout the process. It is concluded that spring having 10 number of turns showed less deflection compared to others and more shear stress developed as well. Spring designers would design springs as per requirements during service conditions considering reliability and life cycles. Optimization of size, weight, and shape of springs would make the cost economic and have effects on reliability and life cycles. Some drawback of this study exists. A comparative study could be done using various materials to find out the best results. Analysis of fatigue failure due to cyclic loading would add a significant dimension in this research field.

\section{Acknowledgments}

Authors would like to express their gratefulness to Department of Mechanical Engineering, Chittagong University of Engineering and Technology, Chattogram-4349, Bangladesh for providing financial and experimental facility to do this research work.

\section{References}

[1] Shala, A., Hajrizi, E. and Likaj, R., 2010. Modelling and Simulation of road Vehicle. IFAC Proceedings Volumes, 43(25), pp.65-68.

[2] Putra, T.E. and Machmud, M.N., 2020. Predicting the fatigue life of an automotive coil spring considering road surface roughness. Engineering Failure Analysis, 116, p.104722.

[3] Tsubouchi, T., Takahashi, K. and Kuboki, T., 2014. Development of coiled springs with high rectangular ratio in cross-section. Procedia Engineering, 81, pp.574-579.

[4] Mitra, A.C., Soni, T. and Kiranchand, G.R., 2016. Optimization of automotive suspension system by design of experiments: a nonderivative method. Advances in Acoustics and Vibration, 2016.

[5] Das, S.K., Mukhopadhyay, N.K., Kumar, B.R. and Bhattacharya, D.K., 2007. Failure analysis of a passenger car coil spring. Engineering failure analysis, 14(1), pp.158-163.

[6] Vukelic, G. and Brcic, M., 2016. Failure analysis of a motor vehicle coil spring. Procedia Structural Integrity, 2, pp.29442950.

[7] Nohut, S. and Schneider, G.A., 2009. Failure probability of ceramic coil springs. Journal of the European Ceramic Society, 29(6), pp.1013-1019.

[8] Pastorcic, D., Vukelic, G. and Bozic, Z., 2019. Coil spring failure and fatigue analysis. Engineering Failure Analysis, 99, pp.310-318.

[9] Al Sahlani, A., Khashan, M.K. and KHALEEL, H.H., 2018. Design and analysis of coil spring in vehicles using finite elements method. Int. J. Mech. Product. Eng. Res. Dev, 8(4), pp.615-624.

[10] Logavigneshwaran, S., Sriram, G. and Arunprakash, R., 2015. Design and Analysis of Helical Coil Spring in Suspension System. International journal for trends in engineering \& technology, 9(1), pp. 1-5.

[11] Mulla, T.M., 2016. Fatigue life estimation of helical coil compression spring used in front suspension of a three wheeler vehicle. Proceedings of the modern era research in mechanical engineering-2016 (MERME-16), Urun Islampur, India, 29.

[12] Sreenivasan, M., Kumar, M.D., Krishna, R., Mohanraj, T., Suresh, G., Kumar, D.H. and Charan, A.S., 2020. Finite element analysis of coil spring of a motorcycle suspension system using different fibre materials. Materials Today: Proceedings, 33, pp.275-279.

[13] Sathish, T., Sabarirajan, N., Chandramohan, D. and Karthick, S., 2020. A novel technique to design and production of coil spring in centre lathe. Materials Today: Proceedings, 33, pp.25212523.

[14] Abidin, M.I.Z., Mahmud, J., Abd Latif, M.J. and Jumahat, A., 2013. Experimental and numerical investigation of SUP12 steel coil spring. Procedia Engineering, 68, pp.251-257.

[15] Ekanthappa, J., Shankar, G.S., Amith, B.M. and Gagan, M., 2016, September. Fabrication and experimentation of FRP helical spring. In IOP Conference Series: Materials Science and Engineering (Vol. 149, No. 1, p. 012098). IOP Publishing.

[16] Pawar, H.B. and Desale, D.D., 2018. Optimization of three wheeler front suspension coil spring. Procedia manufacturing, 20, pp.428-433.

[17] Kim, K.T., 2010. A study on mechanical properties and flowinduced vibrations of coil-shaped holddown spring. Nuclear engineering and design, 240(4), pp.747-755. 